\title{
A PercepÇão sobre a AceitaÇÃo e 0 AJuste da TECNOLOGIA COMO DetERMinANTES DO USO DO ComérCio Eletrônico como CANAL De Compra
}

\author{
Mauni Leodir Löbler \\ Dautor emAdministraçãopda Universidade Feedal doRioGrande \\ do Sul (UFRGS) eProfessor A guunto do Departamento deCiênias \\ Administrativas da Univesidade Feederal deSanta Mania (UFSM) \\ mllde@@hotmil.com \\ Debora Bobsin \\ Dattoranda emAdininistração pda Universidade \\ Feedaral doRioGrandedo Sul (UFRGS) eProfessara \\ da Universidade Feedaral do Pampa - Unipampa \\ dborabobsin@gmil.com \\ Monize Sâmara Visentini \\ Dattoranda emAdministração pda Univesidade \\ Feelaal do RioGrandedo Sul (UFRGS) \\ monizesvisantini@gmail.com \\ Kelmara Mendes Vieira \\ Dautara emAdministração pda Univesidade Federal \\ doRioGrandedbSul (UFRGS) eProfessara Adjun- \\ ta doDepartamentodeCiênias Administrativas da \\ Universidade Feelaal deSanta Mania (UFSM) \\ kemara@smil.ufsmbr
}

\section{RESUMO}

O objetivo deste trabalho é verificar se os fatores intenção de uso, facilidade de uso percebida e 0 ajuste entre a tecnologia e a tarefa de comprar impactam no uso efetivo da Internet como canal de compra. Através de uma pesquisa surveyaplicada a 227 pessoas que já compraram pela Internet, chegou-se à conclusão de que a adequação entre a tecnologia e a tarefa explica a utilidade percebida pelos indivíduos. A intenção de usar o canal comércio eletrônico é fortemente explicada pela utilidade percebida e pelo ajuste da tecnologia e a tarefa a ser executada. Os resultados reforçam a ideia de que se aumentadas as informações que o sitefornece ao usuário, melhor ele entenderá sua utilidade, e mais fácil perceberá a realização da compra.

Palavras-chave: Comércio Eletrônico. Teehndogy Aceptance Modd. Task-TedndogyFit. Percepção de Uso. Surve.
Theaimof this paper is toverify if thefactarsintention of use, percived eased-useand thefit between techndogy and buying task impact in the fffetiveuse of theinteme as a buyingdhann. From a survey applied to 227 peeplewho had already purchased from the Interne, it was conduded that thefit between thetechndogy and the task explains the usefilness percived by theindividuals Theintention to use detranic commeneis strangy explained by the pereived usefulness and thetask-techndoy fit to bepeformed Theresilts strengthen theideat that if theinformation provided to theurers by thesites is increed, their usefulness will bebetter undastood by the users who will percivemoreesily theaccomplishment of thepurchase

Keywords: EletranicCommere Tehndogy A ceptanceModd. Task-Techndogy Fit. Percived Usfilness Survey. 


\section{IINTRODUÇÃO}

Com o avanço da globalização de mercados, o contexto empresarial vem apresentando mudanças, e as tecnologias têm contribuído para que essas alterações se solidifiquem. A rede mundial de computadores, a Internet, proporcionou 0 aumento da velocidade com que as informações são trocadas.

Essa rede, conforme Turban $\notin a l$. (2000), tem o potencial de revolucionar a forma de operação das organizações, proporcionando ganhos significativos de produtividade, reinventando processos, reduzindo os custos operacionais. Q uando usada para comercialização, pode ser vista como uma forma de agregar valor ao negócio (SHIH, 2004), pois elimina barreiras de tempo e distância, aproximando o fornecedor dos clientes.

Devido à velocidade de crescimento e ao fato de proporcionar novas maneiras de comunicação, a Internet permite que se mude o modo de conceber e realizar negócios nas organizações, possibilitando, além de interações entre pessoas, povos e culturas, o delineamento de uma nova forma de comercialização (TESTA, LUCIANO e FREITAS, 2006). A opção de ver o produto e poder comprá-lo, imediatamente, não só distingue a Wébde outros meios de comercialização como também cria o motivo pelo qual muitas pessoas a preferem para executar suas compras (JOINES, SCHERER e SCHEUFELE, 2003).

As empresas que reconhecem as oportunidades que a Internet oferece já começaram a estabelecer sua presença onlinecom um eficiente modelo de negócios, o comércio eletrônico, que lhes serve de alicerce (MAYA e OTERO, 2002).

Kalakota e Whinston (1997) percebem o comércio eletrônico como a compra e a venda de informações, produtos e serviços por meio de redes de computadores, enquanto Cameron (1997) define como qualquer negócio transacionado eletronicamente, sendo que essas transações podem ocorrer entre dois parceiros de negócio ou entre um negócio e os consumidores finais.

Cernev e Leite (2005) vêem o comércio eletrônico como um novo paradigma para as transações comerciais, visto que essa forma de comercialização é uma realidade no mundo dos negócios. Diante desses aspectos, é preciso entender as razões que norteiam o crescimento dessa modalidade de comércio. Sabe-se que existem fatores que determinam o comportamento de uso da tecnologia. Nesse sentido, autores como Klopping e McKinney (2004) estudaram o uso do comércio eletrônico baseando-se em modelos de avaliação do comportamento de utilização da TI, utilizando a integração dos modelos TechndogyA ceptanceModd (TAM) ou modelo de aceitação da tecnologia e o Task-Techndogy Fit (TTF) ou ajuste tecnologia-tarefa, os quais, segundo Dishaw e Strong (1999) fornecem uma base teórica ao explorar os fatores que explicam a utilização da TI.

A partir dessa discussão, este estudo visa verificar os fatores que levam as pessoas a comprar por intermédio do comércio eletrônico, abordando os modelos TAM e TTF para descrever e analisar o comportamento do consumidor virtu- al. Este estudo torna-se relevante, pois, a partir do reconhecimento dos motivos que levam os indivíduos a realizar compras utilizando a tecnologia, as empresas poderão melhor atender as necessidades de seus consumidores e incrementar os seus resultados. Além disso, Rodrigues, Jóia e O liveira (2004) indicam que o volume de vendas por meio do comércio eletrônico é crescente; entretanto, os estudos a respeito dos fatores que motivam a frequência de compra no mercado brasileiro não são tão frequentes assim. Tal fato corrobora a realização desta pesquisa, que busca contribuir para o entendimento desse tipo de negócio.

\section{COMÉRCIO ELETRÔNICO}

O comércio eletrônico envolve as negociações de compra, venda e troca de produtos, serviços e informações por redes de computadores ou pela Internet (TURBAN e KING, 2004), o que acarreta grande aplicação de tecnologia de comunicação e de informação (ALBERTIN, 2004) nesse tipo de comercialização. D esse modo, o comércio eletrônico vem transformando as transações comerciais, a sociedade empresarial e a própria Internet. Para K alakota e Whinston (1996), o comércio eletrônico é visto como uma moderna tecnologia de negócios, que direciona as necessidades de organizações, mercados e consumidores, diminuindo custos e aumentando a qualidade das mercadorias e dos serviços e acelerando 0 processo de entrega. Trata-se de uma combinação entre a tecnologia de informação, processos e estratégias de empresas que facilita 0 intercâmbio de informações, produtos e serviços (CHEN, 2000).

Tigre e D ederick (2003) afirmam que o comércio eletrônico, primariamente dominado por empresas virtuais que o utilizavam como canal único de vendas, tem se tornado um instrumento complementar de negócios, adotado mundialmente pela maioria das organizações. Nesse sentido, Zhou, Dai e Zhang (2007) destacam que com a intensificação da competição nas empresas de Internet torna-se ainda mais importante que elas compreendam as características e percepções do seu consumidor.

$\mathrm{Na}$ atualidade, existem diversos tipos de transações relacionadas ao comércio eletrônico; uma das mais conhecidas pelas pessoas que navegam pela rede é o businesstoconsumer (B2C), isto é, negócios entre empresas e consumidores. A essência dessa transação consiste em fornecer informações que possibilitem mais opções de escolha para o consumidor. Sendo assim, a compra B2C caracteriza-se como um evento discreto na forma pontual em que ocorre, já que o consumidor pode mudar de um sitepara outro efetuando compras de artigos semelhantes em lojas diferentes (MAYA E OTERO, 2002).

Segundo o site especializado em comércio eletrônico, 0 ebit-empresa (2010), o faturamento para 0 setor nos primeiros seis meses de 2010 foi de $R$ \$ 6,7 bilhões. Esse valor indica um aumento de $40 \%$ em relação ao primeiro semestre de 2009, quando registrou R $\$$ 4,8 bilhões. Ao final de 2010 espera-se um faturamento de $\mathrm{R} \$ 14,3$ bilhões, o que representaria um crescimento nominal de $35 \%$ se comparado ao resultado de 2009. Complementarmente, a pesquisa Tecnologia 
de Informação e Comunicação de D omicílios e Usuários (TIC D omicílios, 2009) indica que, em comparação com os resultados de 2008, a consulta a preços de produtos ou serviços na Internet cresceu oito pontos percentuais (de $44 \%$ para $52 \%$ ), e o crescimento de compra, seja de produtos ou serviços online cresceu três pontos percentuais (de 16\% para 19\%). Nesse mesmo estudo, entretanto, é destacado que o principal dos fatores de restrição ao uso do e-commerce é a motivação cultural: a maior parte dos respondentes (56\%) afirma que prefere comprar o produto pessoalmente, pois pode vê-lo antes de concretizar a compra. Ao mesmo tempo, 26\% alegam preocupação com a segurança ou privacidade e $22 \%$ não confiam no produto que irão receber.

Percebe-se, assim, alguns aspectos limitadores do comércio eletrônico. Rodrigues, Joia e O liveira (2004) acrescentam o tempo de espera para a entrega do produto e a impossibilidade de contato físico. Klopping e Mc Kinney (2004) constataram que das compras potenciais pela Internet, $67 \%$ são abandonadas por falta de um atendimento ao consumidor em tempo real. Sendo assim, os autores declaram a relevância de buscar 0 entendimento de quais fatores influenciam na participação dos consumidores virtuais.

As capacidades geradas pela adoção do comércio eletrônico são definidas a partir do uso intensivo de tecnologias que permitem, entre outros recursos, acesso eletrônico a serviços, entrega on-linede informação e serviços, eliminação de barreiras entre empresa-cliente (businesstoconsume) e empresa-empresa (businessto-business) (SHAW, 1999), comunicações (CLE MENTE, 1998) e transações on-line

Diversos modelos teóricos têm sido criados para se conhecer o perfil dos usuários da Tecnologia de Informação (CHEN, 2000). Um modelo desenvolvido para a avaliação da aceitação de instrumentos de TI pelos usuários é o modelo TAM. Embora esteja diretamente relacionado à explicação sobre a concordância dos usuários dos sistemas de informação, pesquisadores já o validaram como modelo teórico para descrever o comportamento do consumidor do comércio eletrônico (MO NSUWE, DE LLAERT eRUYTER, 2004; KLOPPING e MCKINNEY, 2004). Visto que esse modelo aborda 0 comportamento e a atitude do usuário frente às tecnologias, analisando questões como facilidade de uso percebida, utilidade percebida e atitude e intenção de uso, entende-se a sua validade de aplicação ao comércio eletrônico.

Klopping e McKinney (2004) analisaram o comércio eletrônico integrando o modelo TAM ao modelo TTF; apesar de cada modelo possuir uma boa capacidade de explicação, um modelo que inter-relacione os dois pode oferecer um acréscimo significativo de confiabilidade. Nesse sentido, Wu e Wang (2005) afirmam que muitas pesquisas demonstram a necessidade de acréscimo de fatores ao modelo TAM, para que ele se torne ainda mais confiável.

O s dois construtos que servem de base para o Modelo TAM são: a utilidade percebida e a facilidade de uso percebida (DAVIS, 1989). 0 propósito desse modelo é representar 0 impacto de fatores externos relacionados à TI sobre aqueles internos do indivíduo como as crenças, atitudes e intenções de uso (COSTA FILHO e PIRES, 2005). Já o modelo TTF demonstra que a TI será usada exclusivamente se as ferramentas fornecidas pelo sistema sustentarem as atividades do usuário. Assim, os usuários escolherão as ferramentas e os métodos que lhes permitam completar a tarefa da melhor forma (D ISHAW e STRONG, 1999).

\section{MODELO TAM (TECHNOLOGYACCEPTANCE MODEL) - MODELO DE ACEITAÇÃO DA TECNOLOGIA.}

A aceitação ou adoção da Tecnologia da Informação tem recebido, desde a década passada, especial atenção. Alguns modelos teóricos têm sido propostos para explicar 0 comportamento de aceitação dos usuários de sistemas de informações. Entre eles, o modelo de aceitação de tecnologia (TAM), desenvolvido por D avis (1989), que vem sendo amplamente aplicado e empiricamente testado (MA e LIU, 2004; TEO, LIM e LAI, 1999; WU e WANG, 2005; DISHAW e STRONG, 1999; SCHNEBERGER, AMOROSO e DURFEE, 2007; SEEMAN e GIBSON, 2009).

A intenção de desenvolvimento do modelo TAM originou-se de um contrato com a IBM-Canadá, nos meados dos anos 80, para avaliar o potencial de mercado para novos produtos da marca (DAVIS e VE NKATE SH, 1996). O s autores destacam que o modelo foi projetado para compreender a relação causal entre variáveis externas de aceitação dos usuários e 0 uso real do computador, buscando entender o comportamento desse usuário por meio do conhecimento da utilidade e da facilidade de utilização percebida por ele. 0 modelo tem sido largamente utilizado em pesquisas, para compreender os fatores que envolvem a adoção e a utilização de uma tecnologia (SILVA, 2006).

A utilidade percebida (DAVIS, 1989) caracteriza-se como o grau pelo qual a pessoa acredita que usando um sistema particular pode incrementar o seu trabalho; e a facilidade de uso percebida, como as expectativas pelas quais a pessoa acredita que ao utilizar um sistema tecnológico pode se isentar do esforço físico ou mental ao desempenhar suas atividades.

Lederer $\&$ al. (2000) citam duas pesquisas desenvolvidas com o modelo TAM tendo como implicação a WEB. Em uma delas (TE O, LIM e LAI, 1999), verificou-se que a utilidade e a facilidade de uso percebida predisseram o uso, mas que a utilidade de uso percebida teve um efeito mais significante. Na outra, identificou-se que a facilidade de uso explica a utilização da web (MO RRIS e D ILLON, 1997).

Q uando se trata de comércio eletrônico, o uso deve ser relacionado à forma como o consumidor observa a tecnologia da web em relação ao desempenho de sua tarefa (KLO PPING e MCKINNEY, 2004). Os autores D ishaw e Strong (1999) demonstraram a eficácia do uso combinado dos modelos TAM e TTF para trabalhos de adoção de tecnologia, que fornecem, quando reunidos, um modelo mais significativo do que quando utilizados separadamente.

0 modelo TAM (Figura 1) sugere que os indivíduos usarão a informática se acreditarem que esse uso fornecerá resultados positivos, focalizando-se na facilidade de uso per- 
cebida e na utilidade percebida (IGBARIA e IIVARI, 1995). 0 propósito desse modelo é criar uma base para listar o impacto de fatores externos sobre aqueles internos do usuário como as crenças, atitudes e intenções de uso (COSTA FILHO e PIRES, 2005). De acordo com Davis, Bagozzi e Warshaw (1989) esse é um dos modelos mais influentes para pesquisar a aceitação dos sistemas de informação.

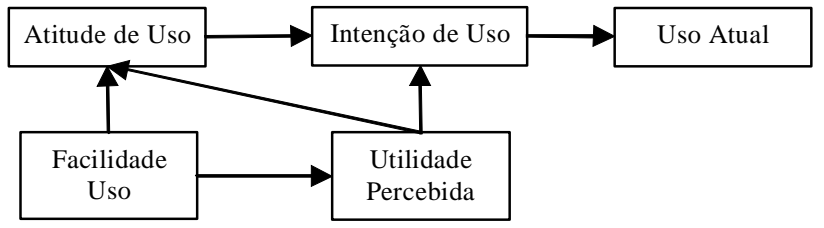

Figura 1: Modelo de aceitação da tecnologia (TAM)

Fonte: D ishaw e Strong (1999).

A Figura 1 apresenta as relações entre os construtos que formam o Modelo TAM. A facilidade de uso percebida mede o grau de uso da tecnologia em que 0 indivíduo acredita não exigir muito esforço mental ou físico (VENKATESH e BALA, 2009), além de observar a percepção do usuário quanto à facilidade de aprendizado e de operação da tecnologia. 0 construto utilidade percebida avalia quanto 0 indivíduo acredita no uso da tecnologia para melhorar o desempenho no trabalho (SILVA, 2006). O bservando o comércio eletrônico, esse fator mede o grau em que os consumidores acreditam que uma tecnologia, em particular, facilita 0 processo de transação (PAVLOU, 2003).

A utilidade percebida é influenciada pela facilidade de uso, e esses dois fatores interferem na atitude de uso da tecnologia. A intenção de uso é formada pela atitude e pela utilidade, e compreende a pretensão dos indivíduos em usar a tecnologia, identificando se as pessoas têm preferência por usar os sistemas baseados em computador ao invés de métodos manuais (DISHAW e STRO NG (1999), ou seja, se preterem o comércio tradicional pelo comércio eletrônico. E por fim, as medidas de uso evidenciam o tempo despendido com a tecnologia, o uso efetivo do comércio eletrônico, o que pode ser observado pelas horas nos sites de consumo e pelo número de transações realizadas. 0 modelo TAM foi reaplicado ao longo do tempo, sendo desenvolvidas algumas extensões como o TAM2 (VENKATESH e DAVIS, 2000) e, mais recentemente, o TAM 3 de Venkatesh e Bala (2009).

\section{MODELO TTF (TASK-TECHNOLOGY FIT) - MODELO AJUSTE TECNOLOGIA-TAREFA}

$O$ modelo TTF, de Goodhue (1995), sugere que a adoção da tecnologia depende de quanto ela cumpre as exigências de uma tarefa particular (KLOPPING e McKINNEY, 2004). D e acordo com Dishaw e Strong (1999), esse modelo demonstra que a tecnologia será usada exclusivamente se as opções fornecidas pelo sistema (suporte) sustentam as atividades do usuário. Racionalmente, os usuários escolherão as ferramentas e os métodos que lhes permitam completar a tarefa da melhor forma. Os sistemas tecnológicos que não ofereçam vantagens suficientes aos usuários não serão utilizados.
Q uando os usuários percebem que a tecnologia utilizada é capaz de suportar a sua tarefa, eles passam a exibir melhores performances (LEE, CHENG e CHENG, 2007). Os autores ainda complementam que uma tecnologia capaz de suportar uma tarefa é aquela que possui funcionalidade, reduz custos de execução e faz com que a tarefa seja executada mais facilmente.

O grau do ajuste da tarefa e da tecnologia é afetado pelas interações entre as características da tarefa, das funcionalidades da tecnologia, e da personalidade dos usuários. 0 ajuste da tarefa-tecnologia melhora quando a relação entre esses três aspectos é estreitada. Além disso, as características diferentes da tarefa requererão a sustentação das funcionalidades diferentes da tecnologia (LEE, CHENG e CHENG, 2007).

O modelo TTF, segundo D'Ambra e Rice (2001), fornece bases para ajudar na identificação das características dos usuários da WEB. Isso porque explica o uso e a avaliação da WEB independentemente, ou seja, permite a identificação potencial de conceitos e escalas para cada indivíduo.

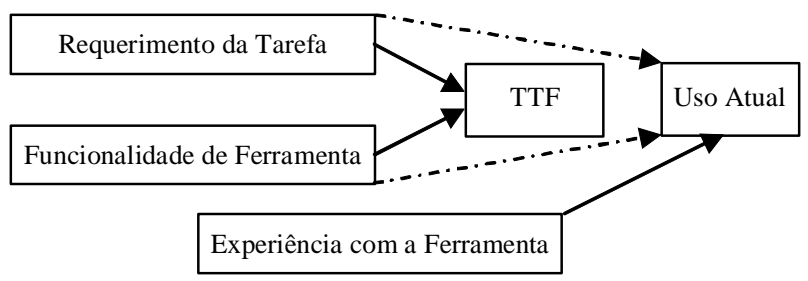

Figura 2: Modelo Ajuste Tecnologia-Tarefa (TTF)

Fonte: D ishaw e Strong (1999).

O modelo TTF indica que o uso da tecnologia é influenciado pelo ajuste existente entre os requisitos das tarefas realizadas e as características de funcionalidade da tecnologia. Assim, quanto mais de acordo com as atividades desenvolvidas o sistema estiver mais será utilizado, e melhor será o seu desempenho (GOODHUE e THO MPSO N, 1995). Esses autores entendem que a performance do indivíduo na realização de uma atividade sofre interferência da relação existente entre as características da tecnologia e as características do trabalho; assim, o modelo tem foco nas tarefas do usuário e nas funcionalidades da tecnologia disponível (D ISHAW e STRONG, 1999), que, quando ajustadas, tendem a aumentar o nível de utilização da ferramenta tecnológica.

Os principais construtos do modelo são os requerimentos das tarefas e a funcionalidade da ferramenta. As tarefas podem ser compreendidas como as ações realizadas pelos indivíduos para transformar as entradas em saídas (CANE e McCARTH, 2009). As características da tarefa, ou os seus requisitos, envolvem suas peculiaridades quanto ao uso da tecnologia para a sua execução. As tecnologias são as ferramentas que podem ser utilizadas na realização das atividades (CANE e McCARTH, 2009).

Além desses fatores, o modelo também apresenta 0 ajuste tecnologia-tarefa (TTF), que engloba as correspondências entre as tarefas e a tecnologia. Esse construto apresenta variáveis que abarcam questões sobre tarefa e tecnologia con- 
juntamente, abarcando aspectos como localização, atualização e confiabilidade dos dados e das informações (ZIGURS e KHAZANCHI, 2008). A experiência com a tecnologia discute 0 conhecimento do usuário quanto ao manuseio e às funcionalidades da tecnologia, e interfere na utilização do sistema da mesma forma que 0 ajuste tarefa-tecnologia.

\section{MODELOS TAM E TTF COMBINADOS}

O s modelos TAM e TTF são especialmente utilizados para compreender o comportamento humano no domínio dos sistemas de informação (CHE N, 2000). Porém, há algumas diferenças significativas entre eles, como a não adoção no modelo TAM de uma variável inovadora: a compatibilidade. A compatibilidade é descrita como o grau pelo qual uma inovação é percebida como consistente, com a existência de valores, experiências passadas e as necessidades daqueles que adotam tal inovação. Uma grande compatibilidade resulta em uma taxa mais rápida de adoção da tecnologia. Essa variável, porém, é reconhecida pelo modelo TTF. Nele, a avaliação dos usuários sobre 0 ajuste entre a tecnologia e a tarefa é determinada por características da tarefa, características individuais e por sistemas de informação e serviço (CHEN, 2000).

Esses argumentos, aliados ao fato de que ao utilizar 0 modelo TTF juntamente ao modelo TAM indicam dois aspectos diferentes sobre as escolhas dos usuários de tecnologias (foco na tarefa e foco nas atitudes), apontam a importância de se aprofundar estudos que associem ambos os métodos. Essa combinação gera uma melhor explicação sobre o uso da tecnologia do que somente a avaliação das atitudes (TAM) ou tarefas (TTF) a serem executadas pelos usuários (D ISHAW e STRO NG, 1999).

No trabalho de Dishaw e Strong (1999) é proposta uma combinação, com elevado grau de complexidade, devido à utilização de todos os fatores na sua forma original. A integração proposta pode ser visualizada na Figura 3. Os autores desse modelo combinado partem do argumento de $\mathrm{G}$ oodhue (1995), que vincula o ajuste tecnologia-tarefa com os modelos comportamentais que explicam o uso da tecnologia.

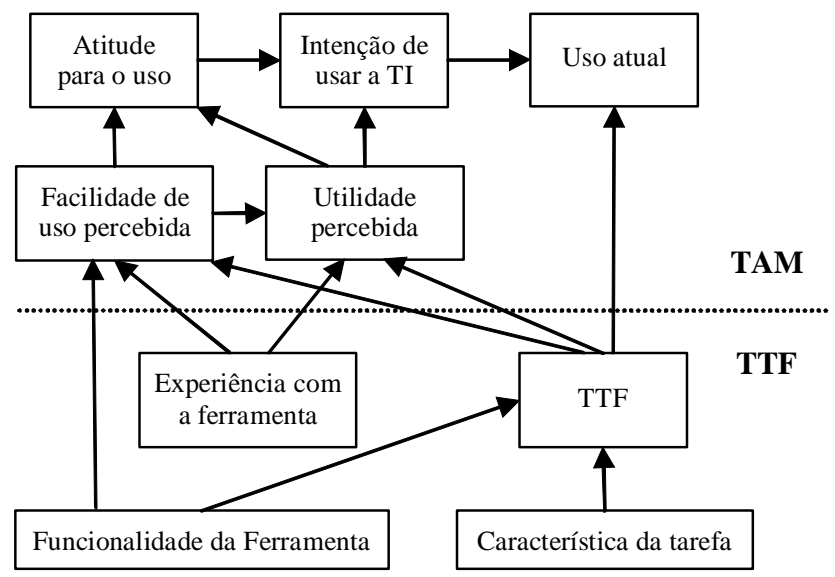

Figura 3: Modelo TAM e TTF combinados

Fonte: D ishaw e Strong (1999).
O s modelos são combinados, tornando suscetível uma melhor explicação do uso da tecnologia. Nesse sentido, Dishaw e Strong (1999) afirmam que o modelo TTF determina, em parte, três variáveis do modelo TAM, sendo que a utilização está presente nos dois modelos. A facilidade de uso e a utilidade percebida são influenciadas pelo modelo de ajuste tecnologia-tarefa, portanto as crenças dos usuários sobre esses fatores são suscetíveis de serem desenvolvidas, em parte, a partir das características da tecnologia e das tarefas realizadas. Além disso, esses dois construtos do modelo TAM, indiretamente, incluem aspectos da tecnologia e das tarefas (DISHAW e STRONG, 1999), pois a noção de utilidade do sistema indica que ele é útil para alguma coisa, ou seja, que a tecnologia tem utilidade para essa tarefa. A facilidade de uso deve ser determinada pela funcionalidade disponível na tarefa e pela experiência do usuário com a tecnologia; portanto, as ferramentas com mais funcionalidades têm maior probabilidade de ser consideradas mais difíceis de usar. No modelo integrado, a experiência com o sistema tem efeito sobre a facilidade de uso, enquanto no modelo TTF esse efeito é direto sobre a utilização da tecnologia.

Em outro trabalho, os autores Klopping e McKinney (2004) combinaram os modelos TTF e TAM para melhor explicar o comportamento do usuário do comércio eletrônico, a partir de uma adaptação do modelo TAM original (DAVIS, 1989). 0 novo modelo (Figura 4) utiliza três fatores para explicar o uso atual, enquanto no modelo original essa explicação era fornecida por quatro fatores, que incluía 0 fator "atitude para o uso". D e acordo com D avis e Venkatesh (1996), pode-se excluir o fator "atitude para o uso" no modelo final do TAM, pois ele não mensura, em sua totalidade, o efeito da "utilidade percebida" sobre a "intenção de uso".

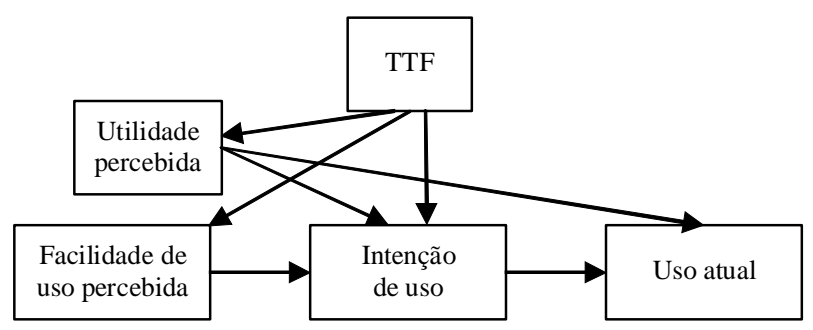

Figura 4: Modelo TAM e TTF combinados

Fonte: Klopping e McKinney, (2004).

No modelo TAM, a "atitude para 0 uso" e a "intenção de uso" unem-se no fator único "intenção de uso". 0 modelo TTF é uma combinação entre a tarefa e a tecnologia e 0 consequente uso dessa tecnologia. Nesse modelo (Figura 4), o TTF é mensurado diretamente, conforme feito anteriormente por Klopping e McKinney (2004). Estando ajustadas tarefa e tecnologia, tem-se a explicação da facilidade de utilizar, da intenção de usar e da utilidade percebida. A utilidade percebida implica na intenção de uso, e essa última implica no uso atual da tecnologia.

No presente artigo, utilizar-se-á a combinação proposta por Klopping e McKinney (2004) por se tratar de um 
modelo mais simplificado e com maior facilidade de entendimento, devido ao modelo TTF ser mensurado em um único construto, pois, para os autores, o comportamento de uso pode estar relacionado à percepção do individuo em relação ao ajuste entre a tarefa e a tecnologia. Além desses motivos, o modelo foi escolhido por ter sido aplicado por Klopping e McKinney (2004) em um estudo sobre comércio eletrônico, estando assim validado para esse objeto de análise.

\section{MÉTODO DE PESQUISA}

Este estudo apresentou caráter descritivo, em que foi realizada uma pesquisa survey, a qual tem três objetivos gerais: descrição, explicação e exploração. A maioria dos estudos tem mais de um objetivo; neste, serão utilizados os três conjuntamente - a exploração, com o intuito de descobrir novas relações; a descrição, com a intenção de descrever 0 fenômeno observado, e a explicação, com o fim de encontrar respostas acerca do uso ou não do comércio eletrônico.

A técnica de pesquisa compreendeu um questionário (ANEXO 1), que permite padronização e provoca informações específicas em virtude de sua estruturação (MALHOTRA, 2001). As questões foram escalonadas em escala Tipo Liket, variando de "1" (discordo plenamente) a " 5 " (concordo plenamente), exceto as de número 5.1 e 5.2, que também foram escalonadas, porém com outra mensuração por se tratarem de quantificação. Os questionários aplicados neste trabalho apresentaram um índice de confiança de $95 \%$ e erro amostral de $5 \%$.

$\mathrm{O}$ universo da pesquisa são os indivíduos que utilizam o comércio eletrônico para a realização de suas compras. A população considerada nesta pesquisa foram os funcionários e estudantes da Universidade Federal de Santa Maria (UFSM). Considera-se que todos têm acesso à Internet e nível social e cultural suficiente para empreender uma compra pela rede mundial. Foi sorteada uma amostra significativa da população estudada, entrevistando-se 520 indivíduos, dos quais 227 já utilizaram a Internet como canal de compras. Assim, esses últimos compuseram a base de análise, sendo 130 homens e 97 mulheres, com média de idade de 31 anos. A maioria dos respondentes pertence às Classes A2 e B1, totalizando essas duas classes, em média, $42 \%$ dos respondentes.

\subsection{Modelo Estudado}

Conforme apresentado, este trabalho adota a integração de dois modelos (TAM e TTF) para descrever e avaliar 0 comportamento do consumidor final (B2C) diante do comércio eletrônico.

O modelo TAM será medido por meio dos construtos: utilidade percebida, facilidade de uso percebida e intenção de uso. 0 modelo integrado não mede a atitude para uso, pois, de acordo com D avis e Venkatesh (1996), as evidências empíricas indicam que se pode excluir esse fator no modelo final do TAM porque ele não mensura, em sua totalidade, 0 efeito da utilidade percebida sobre a intenção de uso.

0 modelo TTF será medido em um único construto, 0 qual observa a relação entre as tarefas realizadas pelo usuário e as características da tecnologia e das informações que ela disponibiliza.

As variáveis do modelo testado empiricamente, nesta pesquisa, podem ser visualizadas no Quadro 1.

\begin{tabular}{|c|c|c|}
\hline FATOR & $\begin{array}{l}\text { CODIGO DA } \\
\text { VARIÁVEL }\end{array}$ & VARIÁVEL \\
\hline \multirow{7}{*}{ TTF (1) } & 1.1 & Informações suficientemente detalhadas sobre os produtos de seu interesse são mantidas nos sites. \\
\hline & 1.2 & Nos sites visitados, informações sobre os produtos são óbvias e fáceis de encontrar. \\
\hline & 1.3 & Eu posso encontrar informações sobre os produtos rapidamente nos sites quando eu necessito. \\
\hline & 1.4 & $\begin{array}{l}\text { A informação do produto on-lineque eu uso ou gostaria de acessar é exata o bastante para meu } \\
\text { objetivo. }\end{array}$ \\
\hline & 1.5 & A informação do produto onlinede que eu necessito está apresentado de forma clara. \\
\hline & 1.6 & A informação do produto onlinemantida no site é suficiente para realizar minhas compras. \\
\hline & 1.7 & $\begin{array}{l}\text { A informação do produto on-lineé armazenada de diferentes formas, que é difícil saber quais } \\
\text { usar efetivamente. }\end{array}$ \\
\hline \multirow{3}{*}{ USO (2) } & 2.1 & Em média, quantos diferentes sites de compras anlinevocê visita durante um mês. \\
\hline & 2.2 & Em geral, quanto tempo você despende nas compras on-linepor semana. \\
\hline & 2.3 & Em média, com que frequência você usa a Internet para suas atividades de compras. \\
\hline \multirow{2}{*}{$\begin{array}{l}\text { FACILIDADE } \\
\text { (3) }\end{array}$} & 3.1 & E difícil aprender a utilizar a Internet para realizar minhas compras. \\
\hline & 3.2 & Levei muito tempo para aprender a usar a Internet para minhas de compras. \\
\hline \multirow{3}{*}{$\begin{array}{l}\text { UTILIDADE } \\
\text { (4) }\end{array}$} & 4.1 & A realização de compras é mais rápida na Internet do que no modo tradicional \\
\hline & 4.2 & Usar a Internet toma mais fácil realizar minhas compras. \\
\hline & 4.3 & Acho a Internet útil para minhas atividades de compras. \\
\hline \multirow{2}{*}{$\begin{array}{l}\text { INTENÇÃO } \\
(5)\end{array}$} & 5.1 & $\begin{array}{l}\text { Na minha opinião, deve ser muito importante usar a Internet para minhas compras adicional- } \\
\text { mente ao método tradicional. }\end{array}$ \\
\hline & 5.2 & Eu gosto de usar a Internet para minhas compras. \\
\hline
\end{tabular}

Quadro 1: Variáveis

Fonte: Klopping e Mckinney (2004). 

das são:

Com base nas discussões teóricas, as hipóteses analisa-

H1: TTF influencia positivamente a utilidade percebida.

H2: TTF influencia positivamente a facilidade de uso percebida.

H3: TTF influencia positivamente a intenção de uso.

H4: A utilidade percebida influencia positivamente a intenção de uso.

H5: A facilidade de uso percebida influencia positivamente a intenção de uso.

H6: A intenção de uso influencia positivamente 0 uso atual.

Sendo assim, identifica-se, na Figura 4, o modelo de pesquisa analisado.
(OLIVEIRA NETO e RICCIO, 2003). Identificada a confiabilidade dos construtos, avaliou-se as relações entre os fatores e o conjunto de hipóteses.

As medidas de ajuste analisadas foram as medidas absolutas de ajuste e as medidas comparativas de ajuste. Kline (1998) expõe que as medidas absolutas de ajuste avaliam 0 grau em que o modelo prediz a matriz de covariância ou correlação observada, enquanto as medidas comparativas servem para comparar o modelo proposto ao modelo nulo.

O s índices de ajuste observados foram: c2 (qui-quadrado), Root Mean Square Residual (RMR), Root Mean Square Error of Aproximation (RMSEA), Goodness-of-fit (GFI), Comparative Fit Index (CFI), Normed Fit Index (NFI) e Tucker-Lewis Index ou Non-Normed Fit Index (NNFI).

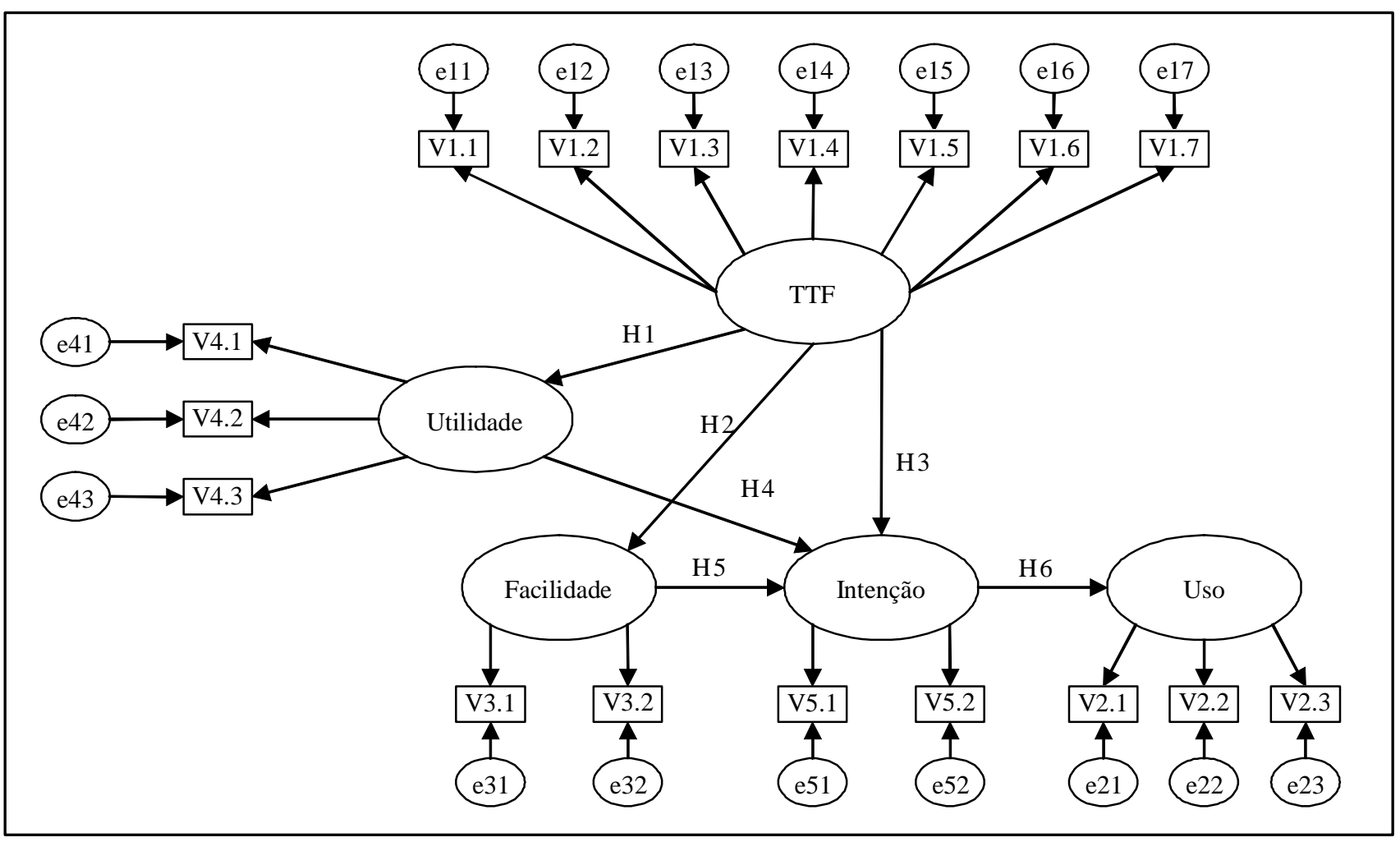

Figura 5: Modelo proposto inicial

Fonte: Elaborado pelos autores.

Visto que o modelo exige um exame simultâneo de diversas relações de dependência, optou-se por trabalhar com a modelagem de equações estruturais (MEE), pois Hair $\notin \mathrm{al}$. (2005) afirmam que essa técnica é útil quando variáveis dependentes tornam-se independentes em subsequentes relações de dependência.

A análise dos resultados foi realizada em dois momentos. Primeiramente pelo alfa de Cronbach dos construtos, 0 qual indica a confiabilidade dos fatores, avaliando o grau de consistência entre múltiplas medidas de uma variável (CHURCHILL, 1979), estimando a validade das medidas, ou seja, a sua conformidade quanto ao fim a que se destinam
Um resultado não-significativo para a estatística quiquadrado indica que os dados se ajustam ao modelo. Hair \& al. (2005) explicam que pode ser analisada a relação qui-quadrado/ graus de liberdade, dividindo o primeiro pelo segundo; para alguns autores esse valor deve ser menor que três. Os autores mostram que quando o RMR for igual a zero, 0 ajuste do modelo é perfeito; valores menores que 0,10 são aceitáveis. Já o RMSEA deve apresentar valores menores que 0,08, enquanto o GFI varia de zero (ajuste ruim) a um (ajuste perfeito). O s valores aceitáveis para as demais medidas, CFI, NFI e NNFI, são acima de 0,9 (K LINE, 1998). A análise dos dados foi realizada com o suporte do pacote estatístico SPSS e o satvarepara modelagem de equações estruturais AMO ${ }^{\mathrm{TM}}$. 


\section{ANÁLISE DOS RESULTADOS}

Visto que os fatores do modelo TAM e TTF integrados para o comércio eletrônico já foram validados nos estudos de Klopping e McKinney (2004) e Löbler, Visentini eVieira (2006), partiu-se para a análise do modelo estrutural, a qual se efetivou com a avaliação dos índices de ajustamento e do valor de significância dos coeficientes. A Tabela 1 permite que sejam verificados os resultados obtidos com o modelo proposto.

Tabela 1: Coeficientes padronizados e significâncias das relações do modelo proposto

\begin{tabular}{c|lc|c|c}
\hline Hipótese & \multicolumn{2}{|c|}{ Relação } & $\begin{array}{c}\text { Coef. } \\
\text { Padronizado }\end{array}$ & Z \\
\hline H1 & TTF & $--->$ Utilidade & 0,506 & $6,02 * * *$ \\
H2 & TTF & ---> Facilidade & 0,265 & $3,406 * * *$ \\
H3 & TTF & $--->$ Intenção & 0,375 & $4,499 * * *$ \\
H4 & Utilidade ---> Intenção & 0,561 & $5,883 * * *$ \\
H5 & Facilidade---> Intenção & 0,328 & $4,257 * * *$ \\
H6 & Intenção & $--->$ Uso & 0,484 & $4,775 * * *$ \\
\hline
\end{tabular}

***, significativos ao nível de $1 \%$

Fonte: Elaborado pelos autores, com base nos dados da pesquisa.

O qui-quadrado apresentou resultado significativo, além de a relação qui-quadrado/ graus de liberdade ter mostrado um valor acima do limite de três, indicado por Kline (1998). Os índices CFI, NFI e NNFI apresentaram resultados menores que 0,9, e o RMSEA ficou acima de 0,08. 0 RMR e 0 GFI foram os que ofereceram resultados mais próximos dos limites aceitáveis, mas, ainda assim, não satisfatórios. Esses índices são apresentados na Tabela 2.

Tabela 2: Índices de ajuste do modelo proposto

\begin{tabular}{l|c}
\hline \multicolumn{1}{c|}{ Indice } & Valor \\
\hline Qui-quadrado & $315,534 \mathrm{p}(0,000)$ \\
Graus de Liberdade & 84 \\
GFI - G oodness of Fit & 0,82 \\
CFI - Comparative Fit Index & 0,85 \\
NFI - Normed Fit index & 0,80 \\
NNFI - Non Normed Fit Index & 0,81 \\
RMR - Root Mean Square Residual & 0,10 \\
RMSEA - Root Mean Squared Error & 0,11 \\
of Aproximation & \\
\hline
\end{tabular}

Fonte: Elaborado pelos autores, com base nos dados da pesquisa.

Visto que os resultados não indicaram um ajuste satisfatório do modelo proposto, partiu-se para o seu aprimoramento, com base no relatório de modificações sugeridas pelo $\mathrm{AMO} \mathrm{S}^{\mathrm{TM}}$. Foi indicada a retirada da variável 1.7, referente ao fator TTF, e da variável 2.3, relacionada ao uso. Outra alteração foi a inclusão da relação entre os fatores facilidade e utilidade. Segundo Legris, Ingham e Collerette (2003) essa relação existe no modelo original do TAM, pois dos 22 estu- dos analisados pelo autor 17 apresentam essa relação. Isso faz com que, do ponto de vista teórico, seja identificado quão pertinente pode ser a inclusão dessa relação ao modelo. Também foram estabelecidas correlações entre os erros das variáveis, com base nas indicações do software de análise.

Realizados os ajustes, a Tabela 3 apresenta um resumo dos coeficientes padronizados e da significância das variáveis formadoras dos construtos finais.

Tabela 3: Coeficientes padronizados e significância

\begin{tabular}{|c|c|c|c|c|c|c|c|}
\hline 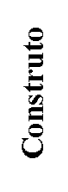 & 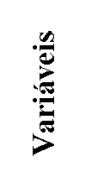 & 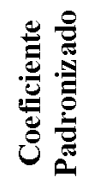 & $\mathbf{N}$ & 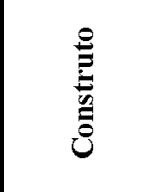 & 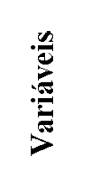 & 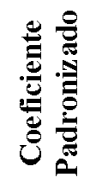 & $\mathbf{N}$ \\
\hline \multirow[t]{6}{*}{$T T F$} & V 1.1 & 0,852 & 1 & \multirow{3}{*}{ Facilidade } & & & \\
\hline & V 1.2 & 0,727 & $10,918 * *$ & & V 3.1 & 0,836 & $6,966 * *$ \\
\hline & V 1.3 & 0,76 & $11,685^{* *}$ & & V 3.2 & 0,787 & 1 \\
\hline & V1.4 & 0,682 & $10,618 * *$ & \multirow[t]{3}{*}{ Utilidade } & V 4.1 & 0,362 & $4,954 * *$ \\
\hline & V1.5 & 0,735 & $11,345 * *$ & & V 4.2 & 0,591 & $6,724 * *$ \\
\hline & V1.6 & 0,613 & $9,142 * *$ & & V 4.3 & 0,899 & 1 \\
\hline \multirow[t]{2}{*}{ Uso } & V 2.1 & 0,662 & 1 & \multirow[t]{2}{*}{ Intençao } & V 5.1 & 0,687 & $8,869 * *$ \\
\hline & V 2.2 & 0,488 & $3,005^{*}$ & & V 5.2 & 0,709 & 1 \\
\hline
\end{tabular}

${ }^{1}$ valor de Z não calculado, pois o parâmetro foi arbitrariamente fixado em 1,0

**, significativo ao nível de $1 \%$; *, significativo ao nível de $5 \%$

Fonte: Elaborado pelos autores, com base nos dados da pesquisa.

A Tabela 4 apresenta os resultados do modelo aprimorado, as hipóteses analisadas e os resultados dos coeficientes, enquanto na Tabela 5 verifica-se os índices de ajuste, que após as alterações realizadas apresentaram resultados satisfatórios.

Tabela 4: Coeficiente padronizado e significância das hipóteses com a inclusão de nova hipótese

\begin{tabular}{c|lc|c|c}
\hline Hipótese & \multicolumn{2}{|c|}{ Relação } & $\begin{array}{c}\text { Coef. } \\
\text { Padronizado }\end{array}$ & Z \\
\hline H1 & TTF & ---> Utilidade & 0,391 & $4,993 * * *$ \\
H2 & TTF & ---> Facilidade & 0,325 & $3,973 * * *$ \\
H3 & TTF & ---> Intenção & 0,444 & $5,073 * * *$ \\
H4 & Utilidade ---> Intenção & 0,530 & $4,443 * * *$ \\
H5 & Facilidade ---> Intenção & 0,238 & $2,969 * * *$ \\
H6 & Intenção & $--->$ Uso & 0,459 & $4,467 * * *$ \\
H7 & Facilidade---> Utilidade & 0,310 & $3,55 * * *$ \\
\hline
\end{tabular}

***, significativo ao nível de $1 \%$; **, significativo ao nível de $5 \%$

Fonte: Elaborado pelos autores, com base nos dados da pesquisa.

Todas as relações apresentaram coeficientes positivos e significativos, sendo assim possível confirmar as hipóteses apresentadas no estudo. Desse modo, verifica-se que o modelo TTF influencia positivamente a utilidade percebida, a facilidade de uso percebida e a intenção de uso; a utilidade percebida e a facilidade de uso percebida, também, influen- 
ciam positivamente a intenção de uso, enquanto a intenção de uso influencia positivamente o uso atual. A nova hipótese (H7) mostra a existência de uma relação direta entre a Facilidade e a Utilidade, e essa relação não foi apresentada no modelo desenvolvido por Klopping e Mckiney (2004). Entretanto, está de acordo com as evidências empíricas encontradas por Dishaw e Strong (1999); os autores Löbler, Visentini e Vieira (2006), ao analisarem especificamente 0 comércio eletrônico, também identificaram essa relação.

Tabela 5: Índices de ajuste do modelo aprimorado

\begin{tabular}{l|c}
\hline \multicolumn{1}{c|}{ Indice } & Valor \\
\hline Qui-quadrado & $166,84 \mathrm{p}(0,000)$ \\
Graus de Liberdade & 76 \\
GFI - G oodness of Fit & 0,90 \\
CFI - Comparative Fit Index & 0,94 \\
NFI - Normed Fit index & 0,90 \\
NNFI - Non Normed Fit Index & 0,92 \\
RMR - Root Mean Square Residual & 0,08 \\
RMSEA - Root Mean Squared Error of & 0,07 \\
Aproximation & \\
\hline
\end{tabular}

Fonte: Elaborado pelos autores, com base nos dados da pesquisa.

No modelo aprimorado, apesar de o qui-quadrado manter-se significativo, a relação entre essa medida e os graus de liberdade apresentou resultado adequado $(2,19)$, indicando que os dados estão ajustados ao modelo. As medidas absolutas de ajuste (GFI, RMR e RMSEA) e as medidas comparativas de ajuste (CFI, NFI, NNFI) apresentaram resultados dentro dos limites aceitáveis, reforçando o bom ajustamento do modelo. A Figura 6 apresenta 0 modelo final proposto.
Com base nesses resultados, percebe-se que as modificações melhoram o modelo; dessa forma, a inclusão da H7 permitiu um incremento nos valores de ajustamento em relação ao modelo proposto.

De modo a complementar a análise realizada, buscouse relacionar os cinco fatores estudados às características de gênero e idade dos participantes da pesquisa. Esses dois aspectos recebem destaque, pois, conforme Slyke, Comunale e Belanger (2002), as diferenças de comportamento entre homens e mulheres diante da tecnologia têm despertado o interesse de pesquisadores, principalmente em relação às tecnologias da Internet; e a influência da idade, na decisão de compra no CE, pode moldar comportamentos de compras orline(STAFFO RD, TURAN e RAISING HANI, 2004).

Para a análise de gênero, procedeu-se a um teste tpara amostras independentes, que visa identificar se há diferença entre as médias apresentadas para cada um dos fatores quando analisadas as percepções de homens e mulheres. Na Tabela 6, são apresentados os resultados desse teste.

Percebe-se que os resultados do teste t para amostras independentes não foram significativos com 95\% de confiança, indicando que não há diferença de percepção entre homens e mulheres no que tange aos fatores relacionados à aceitação do comércio eletrônico como ferramenta para realizar compras e ao seu ajuste às tarefas desempenhadas na Internet.

A variável idade também é considerada neste trabalho devido às grandes divergências, na literatura, sobre a sua influência na compra pela Internet. Z hou, D ai e Z hang (2007) destacam que alguns estudos apresentam relação positiva entre a idade e a ação de comprar pela Rede (STAFFO RD, TURAN e RAISING HANI, 2004), enquanto outros demons-

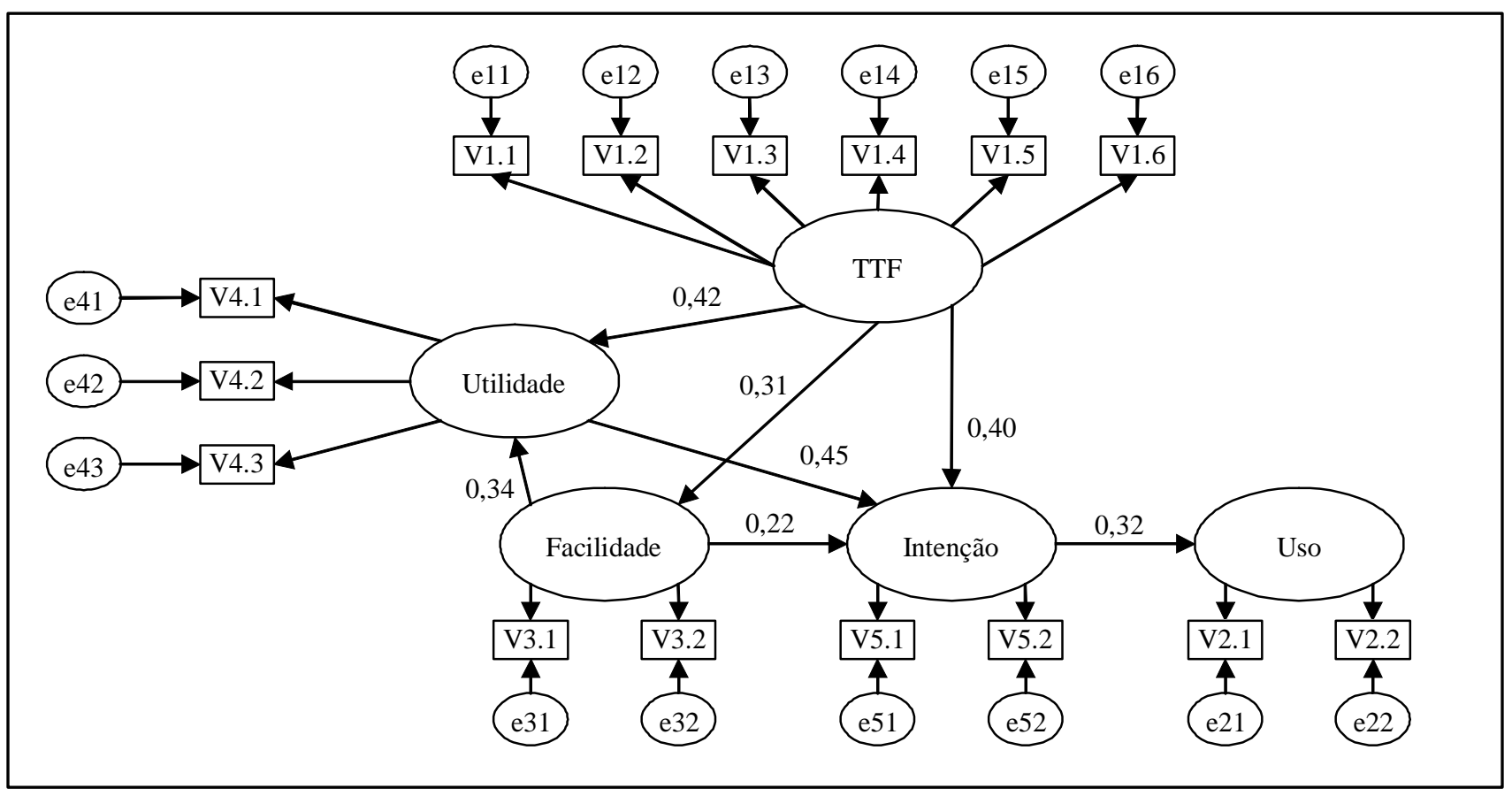

Figura 6: Modelo proposto final

Fonte: Elaborado pelos autores. 
tram a existência de uma relação negativa (JO INES, SCHERER e SCHEUFELE, 2003), ou nenhum relacionamento entre essas variáveis (LI, KUO e RUSSELL, 1999; ROHM e SWAMINATHAN, 2004). Assim, no que diz respeito à análise dos fatores do TAM e TTF para os grupos seccionados por idade, inicialmente classificou-se as idades conforme o quartil a que pertenciam, sendo formados quatro grupo: até 21 anos; de 22 a 26 anos; de 27 a 42 anos; e mais de 42 anos. Posteriormente, realizou-se 0 teste ANOVA entre esses grupos e os fatores analisados, a fim de identificar a existência de diferença de média entre eles. Na Tabela 7, são apresentados os resultados.
Nota-se que somente os fatores utilidade percebida e facilidade de uso percebida apresentaram diferença de média para os grupos analisados. O s demais fatores não foram significativos, indicando que, independentemente da idade, a percepção dos participantes da pesquisa, com relação à intenção de uso, ao ajuste da tecnologia à tarefa e ao uso atual, apresenta similaridades no que tange ao comércio eletrônico.

Com relação à utilidade percebida, visualiza-se que os mais jovens apresentam média maior, apontando que consideram a realização de compras pela Internet mais rápida do que os respondentes de mais idade, bem como uma maior utilidade de compras para adquirir produtos. Talvez em

Tabela 6: Teste tpara amostras independentes entre gênero para os fatores do TAM e TTF

\begin{tabular}{l|cc|cc|cc|cc}
\hline \multirow{2}{*}{ Fatores } & \multicolumn{3}{c|}{ Testes e significância } & \multicolumn{2}{c|}{ Homens } & \multicolumn{2}{c}{ Mulheres } \\
\cline { 2 - 8 } & teste F & Sig. & teste T & Sig. & Média & Desvio-padrão & Média & D esvio-padrão \\
\hline Utilidade percebida & 0,015 & 0,903 & 1,202 & 0,231 & 3,692 & 0,920 & 3,543 & 0,935 \\
Facilidade percebida & 0,107 & 0,744 & 0,376 & 0,708 & 4,142 & 0,965 & 4,093 & 1,006 \\
Intenção de uso & 0,057 & 0,811 & 0,124 & 0,901 & 3,615 & 1,018 & 3,598 & 1,082 \\
TTF & 0,133 & 0,716 & 0,819 & 0,414 & 3,381 & 0,765 & 3,296 & 0,791 \\
Uso atual & 0,208 & 0,649 & 0,738 & 0,461 & 2,303 & 0,752 & 2,227 & 0,783 \\
\hline
\end{tabular}

Fonte: Elaborado pelos autores, com base nos dados da pesquisa.

Tabela 7: Teste ANOVA entre os grupos por idade e os fatores do TAM e TTF

\begin{tabular}{|c|c|c|c|c|c|c|}
\hline Fator & Distribuição idade & $\mathbf{N}$ & Média & Média ao quadrado & Valor do F & Sig. \\
\hline \multirow{5}{*}{ Utilidade percebida } & até 21 anos & 60 & 3,8667 & \multirow{5}{*}{2,92} & \multirow{5}{*}{3,509} & \multirow{5}{*}{0,016} \\
\hline & de 22 a 26 anos & 57 & 3,7251 & & & \\
\hline & de 27 a 42 anos & 56 & 3,5536 & & & \\
\hline & mais de 42 anos & 54 & 3,3395 & & & \\
\hline & total & 227 & 3,6285 & & & \\
\hline \multirow{5}{*}{ Facilidade percebida } & até 21 anos & 60 & 3,775 & \multirow{5}{*}{4,685} & \multirow{5}{*}{5,137} & \multirow{5}{*}{0,002} \\
\hline & de 22 a 26 anos & 57 & 4,0614 & & & \\
\hline & de 27 a 42 anos & 56 & 4,2321 & & & \\
\hline & mais de 42 anos & 54 & 4,4537 & & & \\
\hline & total & 227 & 4,1211 & & & \\
\hline \multirow{5}{*}{ Intenção de uso } & até 21 anos & 60 & 3,5333 & \multirow{5}{*}{0,995} & \multirow{5}{*}{0,912} & \multirow{5}{*}{0,436} \\
\hline & de 22 a 26 anos & 57 & 3,4649 & & & \\
\hline & de 27 a 42 anos & 56 & 3,7054 & & & \\
\hline & mais de 42 anos & 54 & 3,7407 & & & \\
\hline & total & 227 & 3,6079 & & & \\
\hline \multirow{5}{*}{ TTF } & até 21 anos & 60 & 3,4119 & \multirow{5}{*}{0,169} & \multirow{5}{*}{0,278} & \multirow{5}{*}{0,841} \\
\hline & de 22 a 26 anos & 57 & 3,3183 & & & \\
\hline & de 27 a 42 anos & 56 & 3,3571 & & & \\
\hline & mais de 42 anos & 54 & 3,2857 & & & \\
\hline & total & 227 & 3,3449 & & & \\
\hline \multirow{5}{*}{ Facilidade percebida } & até 21 anos & 60 & 2,3611 & \multirow{5}{*}{0,278} & \multirow{5}{*}{0,473} & \multirow{5}{*}{0,701} \\
\hline & de 22 a 26 anos & 57 & 2,2456 & & & \\
\hline & de 27 a 42 anos & 56 & 2,1964 & & & \\
\hline & mais de 42 anos & 54 & 2,2716 & & & \\
\hline & total & 227 & 2,2702 & & & \\
\hline
\end{tabular}

Fonte: Elaborado pelos autores, com base nos dados da pesquisa. 
consequência disso, no fator facilidade de uso observa-se uma maior média para as pessoas mais velhas, indicando, conforme as questões dispostas no questionário, que eles acreditam, mais do que os jovens, ser difícil aprender a utilizar a Internet para realizar compras.

\section{CON SID E RAÇÕ E S FINAIS}

O estudo analisou o comportamento do usuário do comércio eletrônico por meio da combinação do modelo de Aceitação da Tecnologia (TAM) e do modelo de Ajuste Tecnologia-Tarefa (TTF). Os resultados confirmaram que 0 uso dessa ferramenta como meio de compra é explicado em $32 \%$ pelo modelo. Tal constatação é confirmada pelos estudos de Klopping e McKinney (2004), que encontraram um índice de explicação de 33\% para uso, e de Löbler, Visentini e Vieira (2006), que sugeriram um resultado de $29 \%$.

Essa verificação é confirmada pela aceitação das hipóteses analisadas. As primeiras hipóteses, $\mathrm{H} 1, \mathrm{H} 2$ e H3, indicavam que o modelo TTF influencia três variáveis do modelo TAM (utilidade percebida, facilidade de uso percebida, intenção de uso). As hipóteses H4, H5 e H6 apresentavam a relação existente entre as variáveis do modelo TAM.

O s testes estatísticos realizados comprovaram as hipóteses advindas de um modelo inicial, baseado em estudos anteriores; entretanto, foi identificada também a relação entre a facilidade de uso e a utilidade percebida. D essa forma, o modelo final apresentou uma relação adicional (H7), em que a facilidade influencia positivamente a utilidade. Tal relação foi considerada pertinente do ponto de vista teórico. Essa constatação deve ser aprofundada empiricamente, a partir do desenvolvimento de pesquisas futuras que analisem essa relação.

Com base na comprovação das hipóteses, entende-se que a intenção de uso do comércio eletrônico é explicada pela facilidade de uso, utilidade percebida e percepção do indivíduo quanto à adequação do site às compras, ou seja, da tecnologia à tarefa. O bservando os resultados dos três fatores, a intenção é melhor explicada pela utilidade percebida, confirmando outras evidências empíricas (LÖBLER, VISENTINI e VIEIRA, 2006).

A facilidade de uso e a adequação entre a tarefa e a tecnologia explicam a utilidade da Internet como ferramenta para realizar as compras. 0 uso do comércio eletrônico é explicado pela intenção de utilizar tal formato de compra.

Percebe-se que 0 ajuste entre a tarefa e a tecnologia (TTF) influencia os fatores do modelo TAM: utilidade, facilidade e intenção, sendo que sua maior influência ocorre sobre a intenção de uso. Esse resultado pode ser explicado pelo fato de que quando há uma adequação entre a tarefa a ser executada e a tecnologia disponível, o indivíduo deverá entender a mesma ferramenta como útil.

A intenção de usar o canal comércio eletrônico é fortemente explicada pela utilidade percebida e pelo ajuste da tecnologia e a tarefa a ser executada, ou seja, o indivíduo que acredita que o canal de compra comércio eletrônico é útil transfere essa sensação para a intenção de utilizá-lo. Mesmo que a intenção também seja explicada pela facilidade, esse não foi um grande preditor da intenção de usar, significando dizer que o indivíduo poderá achar fácil, mas isso não é suficiente para se traduzir em intenção de utilizar. Esse último resultado pode ser explicado pelo fato da popularização dos computadores, em que achar fácil utilizar a ferramenta não significa um diferencial para a intenção de utilizá-la.

A partir do desenvolvimento de sistemas de comércio eletrônico, o fator chave a ser considerado é o ajuste da tecnologia à tarefa. Isso leva à necessidade de transformar esses sistemas, totalmente ajustáveis à tarefa de comprar, visto que para cada tipo de produto pode haver diferentes tipos de ajustes necessários, pois o comprador espera especificidades dos sistemas dependendo do produto a ser comprado por meio deles.

O utro fator a ser considerado pelas empresas e pelos desenvolvedores envolvidos com comércio eletrônico é a facilidade de uso percebida ao operar o sistema. Facilitar o uso por intermédio de sitescom boa usabilidade impacta na utilidade, que, por sua vez, junto com a sensação de facilidade, impacta muito fortemente na intenção de usar e, consequente, no uso do comércio eletrônico. Isso corrobora a afirmação de Santos (2007), de que a usabilidade é um fator que determina o sucesso de um sistema. Acrescenta o autor que, no caso de sistemas de Internet, principalmente em sites de compra, a usabilidade influencia diretamente o sucesso das vendas.

Ainda com relação ao desenvolvimento de sistemas de comércio eletrônico, este trabalho poderá servir de base para a sua customização, dependendo da idade dos usuários nele cadastrados. Os mais jovens acreditam que o comércio eletrônico é mais útil, o que pode ser considerado normal, visto tratar-se da geração digital, enquanto os mais velhos, ainda que sejam usuários de comércio eletrônico, por fazerem parte da amostra, não o consideram tão útil assim; utilizam esse canal mais por necessidade ou mesmo da adequação do sistema à tarefa que naquele momento se apresenta, ou seja, comprar. Com relação a esse item, sugere-se que as empresas que operam com comércio eletrônico invistam em campanhas dirigidas aos mais velhos para divulgar a utilidade de utilizar esse canal; para o público mais jovem, as campanhas podem focar no produto, pois o canal é visto como útil.

Com relação à facilidade percebida, o público mais velho considera o comércio eletrônico mais difícil de usar. Levando-se em conta a geração digital, facilidade é item relevante para os mais jovens no momento de utilizar a Internet, ainda que seja o comércio eletrônico, pois seu uso faz parte do habitual entre eles. Para os mais velhos, talvez o uso habitual seja menos constante, proporcionando maior dificuldade para utilizar a internet como meio de realizar compras.

Com base nos resultados deste trabalho, embora não fosse seu objetivo inicial, e por isso carece de maior exploração, os desenvolvedores de sistemas de comércio eletrônico não necessitam preocupar-se em customizá-los considerando homens e mulheres, embora possa ser uma variável relevante para diferentes tipos de produtos. Considerando somente o uso do canal comércio eletrônico, objeto deste estudo, não foram demonstradas diferenças entre gênero. 
O s resultados também mostram que, se aumentadas as informações que o sitefornece aos usuários, melhor eles perceberão sua utilidade, e consequentemente mais fácil perceberão a realização da compra. Esses aspectos podem ser potencialmente melhorados, se 0 sitefor elaborado de forma a se adequar às tarefas de compras.

A pesquisa apresentou algumas limitações, como 0 fato de a amostra de pesquisa ser formada por funcionários e estudantes de uma universidade. Além disso, houve certa dificuldade em abranger toda a população, porque não há uma clara identificação dos compradores ou dos potenciais compradores do comércio eletrônico. D eve-se destacar, também, que são poucos os estudos que envolvem os modelos TAM e TTF integrados para o comércio eletrônico, impossibilitando conclusões mais profundas.

Como sugestão para pesquisa futura, tem-se a ampliação da amostra a fim de corroborar os resultados encontrados. Além desse aspecto, é valido que se aumente as variáveis e os fatores que influenciam o uso do comércio eletrônico, a fim de ampliar a explicação do uso efetivo desse meio de compra. Recomenda-se utilizar o modelo combinado de Dishaw e Strong (1999), que ao invés de apresentar 0 construto ajuste tecnologia-tarefa utiliza o modelo TTF completo. Indica-se, ainda, que o comércio eletrônico seja estudado por meio de outros modelos de aceitação da tecnologia e de extensões dos modelos discutidos neste artigo (tais como TAM2, TAM3, UTAUT, entre outros) para que se corroborem os resultados alcançados. Sugere-se, também, que se teste os modelos TAM e TTF integrados para outras formas de utilização da tecnologia, como, por exemplo, as redes sociais virtuais, que são um fenômeno atual.

\section{REFERÊNCIAS}

ALBERTIN, A. L. Comério eletrônico: Modelo, Aspectos e Contribuições de Sua Aplicação. 5. ed., São Paulo: Atlas, 2004.

CAMERON, D. EletronicCommere The New Business Platform for the Internet. Charleston: Computer Technology Research Corp, 1997.

CANE, S.; McCARTHY, R. Analyzing the factors that affect information systems use: a task-technology fit meta-analysis. Jaumal Of Computer Information Systems, p. 108-123, Fall 2009.

CERNEV, A. K.; LEITE, J. C. (2005). Segurança na Internet: a Percepção dos Usuários como Fator de Restrição ao comércio eletrônico no Brasil. In: ENCONTRO ANUAL DA ASSO CIAÇÃO NACIONAL DE PROG RAMAS DE PÓ S-GRAD UAÇÃO EM AD MINISTRAÇÃO, 29, 2005, Brasilia. Anais... Brasília: ANPAD, 2005. CD -RO M.

CHEN, Lei-D a. Consumeraceptancef virtual stares a theoretical model and critical success factors for virtual stores. Memphis, 2000, $144 \mathrm{f}$. Tese (doutorado) - The University of Menphis, 2000.

CLEMENTE, A., PrgitosEmpresaniaisePúdicos São Paulo:A tlas, 1998.

COSTA FILHO, B. A. PIRES, P. J. Avaliação dos Fatores Relacionados na Formação do Índice de Prontidão À Tecnologia TRI (Technology Readiness Index) como Antecedentes do Modelo TAM (Technology Acceptance Model). In: ENCONTRO ANUAL DA ASSOCIAÇÃ̃O NACIONAL DE PROGRAMAS DE PÓSGRAD UAÇÃO EM AD MINISTRA ÇÃ O, 29, 2005, Brasília. Anais.. Brasília: ANPAD, 2005. CD -RO M.
CHURCHILL, G. A. A paradigm for developing better measures of marketing constructs. Jaumal of Markiing Research n. 16, p. 6473, feb. 1979.

D 'AMBRA, J., RICE, R. E., Emerging factors in user evaluation of the Worl Wide Web. InformationandManagenent, v. 38, p. 373-384, 2001.

DAVIS, F. D. Perceived usefulness, perceived ease of use, and user acceptance of information technology. MS Quartely, v. 13, n. 3, p. 319-339, 1989.

DAVIS, F. D., BAG OZZI, R. P., WARSHAW, P. R. User acceptance of computer technology: a comparison of two theoretical models. Managenet Science, v. 35, n. 8, p. 982-1003, 1989.

DAVIS, F. D., VENKATESH, V. A critical assessment of potential measurement biases in the technology acceptance model three experiment. Intemational Joumal of Human-Computer Studies v. 45, n. 1, p.19- 45, Jul 1996.

DISHAW, M. T.; STRONG, D. M. Extending the technology acceptance model with task-technology fit constructs. Informationand Management, v. 36, p. 9-21, 1999.

Ebitempresa. Notíaas do ebit. D isponível em: <https:/ / www. ebitempresa.com.br/ index.htm>. Acesso em: 10 out. 2010.

HAIR JR., J. F. et al. Análise multivariada de dados Porto Alegre: Bookman, 2005.

IG BARIA, M., IIVARI, J. The effects of self-efficacy on computer usage. Onega, v. 23, n. 6, p. 587-605, 1995.

JOINES, J., SCHERER, C., SCHEUFELE, D. Exploring Motivations for Consumer Web Use and Their Implications for ECommerce. Jaumal of Consumer Marketing v. 20, n. 2, p. 90-109, 2003.

KALAKOTA, R, WHINSTON, A. B. EletraicCammereA Manager's Guide. Berkeley Addison Wesley, 1997.

KALAKOTA, R, WHINSTON, A. B. Fronties of detronic commece Addison-Wesley Publishing Company, Inc., 1996.

KLINE, Rex. B. Pniniplesandpradiceof structural equationmodding New York: The Guilford Press, 1998.

KLOPPING, I. M., McKINNEY, E. Extending the Technology Acceptance Model and theTask-Technology Fit Model to Consumer e-Commerce. Information Techndoy, Leming and Peformance Joumal, v. 22, n. 1, p. 35, Spring 2004.

LEDERER, A. L., $\notin$ al. The technology acceptance model and the World Wide Web. Deision Suppat Systems v. 29, p. 269-282, 2000.

LEGRIS, P; ING HAM, J; COLLERETTE, P. Why do people use information technology? A critical review of the technology acceptance model. Information and managenent, v. 40, p. 191-204, 2003. LEE, C., CHENG, H. K., CHENG , H. An empirical study of mobile commerce in insurance industry: Task- technology fit and individual differences. Deision Suppat Systems v. 43, n. 1, p. 95-110, 2007.

LI, H.; KUO, C.; RUSSELL, M. G. The Impact of Perceived Channel Utilities, Shopping O rientations, and Demographics on the Consumer's On-line Buying Behavior. Jarmal of Computer-Mediated Commmication v. 5, n. 2, 1999.

LÖBLER, M. L.; VISENTINI, M. S.; VIEIRA, K. M. A aceitação do comércio eletrônico explicada pelos modelos TAM e TTF combinados. In: ENCONTRO ANUAL DA ASSO CIAÇÃO NACIONAL DE PROG RAMAS DE PÓ S-G RAD UAÇÃO EM AD MINISTRAÇÃO, 30, 2006, Salvador. Anais.. Salvador: ANPAD, 2006. CD-ROM.

MA, Q., LIU, L. The Technology A cceptance Model: A Meta-Analysis of E mpirical Findings. Jarmal of Organizational andEndUserComputing v. 16, n. 1, p. 59, jan/ mar, 2004. 
MALHOTRA, N. Pesquisademarkeing uma orientação aplicada. Porto Alegre: Bookman, 2001.

MAYA, P. C., OTERO, W. I. A Influência do Consumidor na era da Internet. Revista da FAE. Curitiba, v. 5, n. 1, p. 71-81, jan/ abr, 2002. MO NSUWE, T. P., D ELLAERT, B. G. C., RUYTER, K. What drives consumers to shop on-line? A literature rewiew. Intermational Joumal of ServiceIndustry Management, v. 15, n. 1, p. 102-121, 2004.

MORRIS, M. G., DILLON, A. How user perceptions influence software use, decision support systems. IEEE Software, v. 14, n. 4, p. 58-65, jul-aug, 1997.

OLIVEIRA NETO, J. D. de; RICCIO, E. L. Desenvolvimento de um instrumento para mensurar a satisfação do usuário de sistemas de informações. Reista deAdministração v. 38, n. 3, p. 230-241, julset,2003.

PAVLOU, P. Consumer acceptance of eletronic commerce: integrating trust and risk wiht the technology acceptance model. Intemational Jaumal of Eletranic Commece v. 7, n. 3, p. 101-134, 2003.

RO D RIG UES, E. M. T.; JO IA, L. A; OLIVEIRA, L. C. B. de. (2004). Fatores influentes na frequência de compra pela Internet: um estudo exploratório em livrarias virtuais. In: ENCONTRO ANUAL DA ASSO CIAÇÃO NACIO NAL DE PROG RAMAS DE PÓSGRAD UAÇÃO EM AD MINISTRAÇÃO, 28, 2004, Curitiba. Anais.. Curitiba: ANPAD, 2004. CD -RO M.

RO HM, A. J.; SWAMINATHAN, V. A Typology of On-lineShoppers Based on Shopping Motivations. Jaumal of Business Rearch v. 57, n. 7, p. 748-758, 2004.

SCHNEBERG ER, S.; AMO RO SO, D. L.; D URFEE, A. Factors that influence the performance of computer-based assessments: an extension of the technology acceptance model. Jaumal of Computer Information Systems p. 74-87, Winter 2008.

SEEMAN, E.; GIBSON, S. Predicting acceptance of electronic medical records: is the technology acceptance model enough? SAM Advanced Managenent Joumal, p. 21-16, Autumn 2009.

SHAW, M. J. Electronic Commerce: Review of Critical Research Issues. Information Systems Frontiess, v. 1, n. 1, p. 95-106, 1999.

$\mathrm{SHIH}, \mathrm{H}$. P. Extended technology acceptance model of Internet utilization behavior. Information\& Management, v. 41, p. 719-729, 2004.

SILVA, M. F. Fatoreshumanos esuainfluência ma intençãodeusodesistemas de informaçãa 144 fls. Tese (D outorado em Administração) Universidade Federal do Rio de Janeiro, Rio de Janeiro, 2006.

SLYKE, C. V.; COMUNALE, C. L.; BELANGER, F. G ender Differences in Perceptions of Web-Based Shopping. Communications of theACM, v. 45, n. 7, p. 82-86, 2002.

STAFFORD, T. F.; TURAN, A.; RAISING HANI, M. S. International and Cross-Cultural Influence Behavior. Jaumal of Gldbal Information Management, v. 7, n. 2, p. 70-87, 2004.

TEO, T. S. H., LIM, V. K. G., LAI, R. Y. R. Intrinsic and extrinsic motivation in Internet usage. Onega, v. 27, p. 25-37, 1999.

TESTA, M. G., LUCIANO, E. M., FREITAS, H. comércio eletrônico: tendências e necessidades de pesquisa. Rio de Janeiro: RevistaANGRAD, v. 7, n. 1, p.23-42, jan-mar 2006.

TIC D O MICÍLIOS e USUÁRIOS 2009. Reatóno Sódioeconômica D isponível em: <http:/ / www.cetic.br/ usuarios/ tic/ 2009/ analisetic-domicilios2009.pdf>. A cesso em 10 out. 2010.

TIGRE, P. B., DED RICK, J. Mitos e realidades sobre a difusão do comércio eletrônico nas empresas brasileiras. Revista Brasileira de Inovaçãa v. 2, n. 2, p. 377-405, 2003.

TURBAN, E. et al. Eletronic Commare A Managerial Perspective. Ist Ed USA: Prentice Hall, 2000.
TURBAN, E.; KING , D. Comério detrônica estratégia e gestão. São Paulo: Prentice Hall, 2004.

VENKATESH, V. BALA, H. Technology acceptance model 3 and a research agenda on interventions. Deeision Sänes v. 39, n. 2, 2008.

VENKATESH, V.; DAVIS, F. D. A theoretical extension of the technology acceptance model: four longitudinal field studies. Managament Saience v. 46, p. 186-204, 2000.

WU, J. H., WANG , S. C. What drives mobile commerce? An empirical evaluation of the revised technology acceptance model. Infomation \& Mamagement, v. 42, p. 719-729, 2005.

ZHOU, L.; DAI, L.; ZHANG, D. On-lineShopping acceptance model - a critical survey of consumer factors in on-line shopping. Jamal of EletronicCommere Research v. 8, n. 1. p. 41-62, 2007.

ZIGURS, I.; KHAZANCHI, D. From profiles to patterns: a new view of task-technology fit. Information Systems Management, v. 25, p. 8-13, 2008.

Data de Submissão: 12/ 12/ 2007

Data de Aprovação: 05/ 11/ 2010 